\title{
Uma Aula Assente no Ensino Exploratório de Matemática Aliada ao Software GeoGebra
}

\author{
Vania Sara Doneda de Oliveira ${ }^{1}$, Dalva Spiler Brandelero ${ }^{2}$ \\ 1,2 Universidade Estadual do Paraná - Campus de Campo Mourão \\ Campo Mourão - PR - Brasil \\ vania.oliveira28eescola.pr.gov.br, dalvaspiler@hotmail.com
}

\begin{abstract}
This experience report describes a task planned and developed from the perspective of Exploratory Mathematical Teaching using GeoGebra software. The task called Squares was performed in a class of 6th grade of elementary school of a public school in the interior of Paraná / Brazil. The objective was to explore and understand the concept of square area, establishing relations between the side of the square and its area. It is observed that GeoGebra enhances the understanding of square area because it allows the visualization and symbolic interpretation of mathematical concepts, propitiating the perception and comprehension of the objectives of the proposed task.
\end{abstract}

Resumo. Este relato de experiência descreve uma tarefa planejada e desenvolvida na perspectiva do Ensino Exploratório de Matemática com a utilização do software GeoGebra. A tarefa denominada Quadrados foi realizada em uma turma de $6^{\circ}$ Ano do Ensino Fundamental de uma escola pública do interior do Paraná/Brasil. O objetivo foi explorar e compreender o conceito de área do quadrado, estabelecendo relações entre o lado do quadrado e sua área. Observa-se que o GeoGebra potencializa o entendimento de área de quadrado, pois permite a visualização e interpretação simbólica dos conceitos matemáticos favorecendo, ainda, a percepção e compreensão dos objetivos da tarefa proposta.

\section{Introdução}

Experiências de ensino vivenciadas pelas autoras demonstram que práticas docentes que possibilitem o aprendizado são cada vez mais desafiadoras para nós professoras. Refletir sobre nossas experiências em sala de aula é uma prática que pode conferir sentido ao trabalho docente e contribuir para a tomada de decisões que possibilitem conduzir melhorias ao processo de ensino e de aprendizagem.

Dessa forma, desenvolvemos uma tarefa contemplando o conceito de área de quadrados, na perspectiva do Ensino Exploratório de Matemática, em que os alunos, com o auxílio do software GeoGebra, resolveram a atividade. A perspectiva exploratória emerge como uma estratégia em contraposição ao ensino chamado tradicional. Entendemos uma aula tradicional como sendo aquela em que o processo de ensino é centrado no professor, que realiza a transmissão de informação para seus alunos [Oliveira, Menezes e Canavarro 2013].

Para realização da tarefa utilizamos notebooks com sistema Linux Educacional, com o software GeoGebra instalado, com o objetivo de permitir ao aluno conhecer, discutir e explorar o artefato tecnológico, verificando quais seriam as implicações na aprendizagem do conteúdo de área de quadrados. Essa experiência foi realizada em uma turma de $6^{\circ}$ Ano do 
VIII Congresso Brasileiro de Informática na Educação (CBIE 2019)

Anais dos Workshops do VIII Congresso Brasileiro de Informática na Educação (WCBIE 2019)

Ensino Fundamental, com 32 alunos, em uma escola pública do interior do estado do Paraná/Brasil.

Escolhemos o software GeoGebra por ser um programa de geometria dinâmica, de código aberto, que reúne geometria, álgebra, planilha de cálculo, gráficos, probabilidade, estatística e cálculos simbólicos. As janelas de geometria, álgebra e planilha de cálculo estão interligadas. É um software gratuito que está disponível para diversos sistemas operacionais como Linux, Windows e MacOS, podendo ser utilizado também nos smartphones e tablets [GeoGebra 2019].

É de conhecimento comum que as tecnologias estão inseridas no cotidiano de muitas pessoas, sendo para atividades vinculadas a comunicação pessoal e/ou situações de trabalho. Para Basniak (2014, p. 49), "a educação como processo de apropriação cultural não pode ser desvinculada da interferência que a tecnologia exerce na sociedade", por isso é necessário incorporar as tecnologias no processo de ensino e de aprendizagem. Conforme as Diretrizes Curriculares Estaduais de Matemática do Estado do Paraná (2008 p. 65), "no contexto da Educação Matemática, os ambientes gerados por aplicativos informáticos dinamizam os conteúdos curriculares e potencializam o processo pedagógico".

Sabemos que as tecnologias podem ser usufruídas nas práticas docentes, no entanto "uma utilização pertinente da tecnologia ainda permanece relativamente rara" [Unesco 2016 p. 21]. No sentido de refletir sobre o ensino e a aprendizagem de conteúdos matemáticos, aliados às Tecnologias Digitais, nos embasaremos na perspectiva do Ensino Exploratório de Matemática por meio de uma tarefa exploratória. Portanto, nesse relato, abordaremos a utilização do GeoGebra para a representação geométrica de quadrados, com os seguintes objetivos:

- Explorar e compreender o conhecimento do conceito de área do quadrado.

- Retomar e ampliar o conhecimento sobre números racionais positivos.

- Investigar o que acontece com a área do quadrado ao modificar a medida do lado utilizando o controle deslizante do GeoGebra.

- Estabelecer relação entre o lado do quadrado e sua área.

Para a tarefa proposta serão usadas as ferramentas do software GeoGebra e a janela de visualização, apresentando associações de conceitos matemáticos, com diversas representações, como auxiliadores na construção e produção de conhecimento. Ao proporcionar aos alunos tarefas exploratórias, queremos oportunizar o desenvolvimento do trabalho autônomo, fazendo emergir ideias matemáticas, desenvolvendo o trabalho coletivo e incentivando a comunicação oral e escrita.

\section{O Ensino Exploratório de Matemática}

O Ensino Exploratório de Matemática constitui uma perspectiva que se contrapõe ao modelo de transmissão de conhecimento/informação associado às práticas expositivas e diretivas [Ponte 2005]. De acordo com Oliveira, Menezes e Canavarro (2013), o Ensino Exploratório de Matemática sugere que o trabalho seja norteado por uma organização de aulas em fases, as quais os pesquisadores brasileiros assumiram como sendo i) introdução da tarefa, ii) realização da tarefa, iii) discussão da tarefa e iv) sistematização das aprendizagens, as quais caracterizaremos, de forma breve, a partir do olhar de Cyrino e Teixeira (2016):

i) Proposição da tarefa: essa fase é muito importante, pois é neste momento que o professor explica para os alunos a dinâmica da aula, como os alunos irão se organizar para 
VIII Congresso Brasileiro de Informática na Educação (CBIE 2019)

Anais dos Workshops do VIII Congresso Brasileiro de Informática na Educação (WCBIE 2019)

desenvolver a tarefa (em grupo ou individual), o tempo, os recursos e as formas de registro que poderão ser utilizados. Após os alunos receberem a tarefa, é preciso conduzir a gestão de tempo e explicar as formas como farão suas anotações, para posterior socialização. Poderá ainda ser feita leitura coletiva da tarefa de forma que todos compreendam o que precisa ser feito.

ii) Desenvolvimento da tarefa: nessa fase o papel do professor é de observador das estratégias de resolução que os alunos estão desenvolvendo. Nesse momento, é importante o professor não validar respostas corretas ou incorretas, mas questionar sobre como fizeram, buscando fazer com que o próprio aluno perceba se acertou ou errou e justifique suas estratégias e seu modo de pensar.

iii) Discussão da tarefa: essa fase complementa a anterior, pois é o momento de os alunos socializarem no grande grupo o que discutiram ou pensaram na realização da tarefa. Para que seja mais produtiva, o professor pode selecionar resoluções diferentes e que estejam corretas, como também aquelas erradas ou inconsistentes para que, diante de uma discussão coletiva, as conclusões esperadas sejam alcançadas e, dessa forma, ofereça elementos ricos e consistentes para a próxima fase da aula.

iv) Sistematização das aprendizagens: como afirma Canavarro (2011 p. 11) o Ensino Exploratório de Matemática "não advoga que os alunos descobrem sozinhos as ideias matemáticas que devem aprender, nem tão pouco que inventam conceitos e procedimentos ou lhes adivinham os nomes". Ou seja, a mediação do professor é essencial em todo esse processo e não menos importante na última fase. É nela em que ocorrerá a sistematização das ideias matemáticas, suas regras, generalizações, definições, propriedades, entre outras, de forma a fazer com que a tarefa desenvolvida faça sentido para o aluno e que os objetivos delineados sejam alcançados.

\section{A Tarefa}

A elaboração da tarefa, seus objetivos e o quadro de antecipação, o qual prevê possíveis ações, questionamentos dos alunos e como a professora iria agir para não validar ou refutar estratégias de resolução, foram realizados em conjunto pelas autoras. No entanto, uma das professoras autoras ficou responsável por colocar em prática a tarefa, seguindo as fases de uma aula assente na perspectiva exploratória. Para isso optamos, por critérios definidos pela pesquisa, por uma das turmas de $6^{\circ}$ ano do Ensino Fundamental em que a professora é regente.

\section{TAREFA}

Considere cada quadradinho da malha uma unidade de referência para área e siga os seguintes passos:

- Clique na ferramenta controle deslizante.

- Clique na janela de visualização. Abrirá uma nova janela. Escolha mínimo 1 e máximo 12 , incremento 0.1 .

- Clique na ferramenta polígono regular, clique no ponto $(0,0)$ e depois no ponto $(1,0)$, abrirá uma janela solicitando o número de vértices, digite 4 .

- Clique 2 vezes no ponto $B$ e coloque o ponto $(a, 0)$.

- Configure a malha para 1x1 (Eixo X e Eixo Y). 
VIII Congresso Brasileiro de Informática na Educação (CBIE 2019)

Anais dos Workshops do VIII Congresso Brasileiro de Informática na Educação (WCBIE 2019)

Com base no enunciado da questão e embasado em seus conhecimentos sobre geometria, analise e responda os itens abaixo:

1 - Clique na ferramenta Área do GeoGebra, logo após, clique dentro do quadrado construído. Mova o controle deslizante até a posição 2 e observe a área do quadrado. Faça o mesmo com o controle deslizante nas posições indicadas na tabela.

\begin{tabular}{|l|l|l|l|l|l|l|l|l|l|l|l|}
\hline Lado do quadrado & 1 & 2 & & 3 & 4,5 & & 8 & & 10,2 & 15 & \\
\hline Área do quadrado & & & 6,25 & & & 36 & & 81 & & & 400 \\
\hline
\end{tabular}

a) 0 que o GeoGebra fez para calcular a área dessas figuras?

b) Justifique o cálculo feito pelo GeoGebra para determinar o lado dos quadrados de área 6,25; 36; 81 e 400 .

c) Que relação podemos estabelecer entre a área do quadrado e a medida do seu lado? Justifique sua resposta detalhadamente.

d) Se chamarmos a medida do lado de um quadrado de l, como podemos representar a área desse quadrado?

e) Construa um quadrado de qualquer tamanho. Em seguida, construa outro quadrado cujo lado seja o dobro do primeiro. Que relações você pode estabelecer entre a área do primeiro e do segundo quadrado.

Figura 1. Tarefa Quadrados elaborada pelas autoras

\section{A Aula}

A turma foi dividida em 8 equipes, com 4 alunos, e cada equipe foi numerada de 1 a 8 para facilitar a análise dos resultados pelas autoras. Seguindo as fases do Ensino Exploratório de Matemática já citadas, foi realizada a distribuição e leitura da tarefa para garantir que todos a entendessem. Após, cada equipe seguiu os passos descritos para a resolução da tarefa. A professora acompanhou e monitorou cada equipe no desenvolvimento da tarefa, inquirindo e auxiliando com o software, caso fosse necessário. Após o tempo de cinquenta minutos para os alunos desenvolverem a tarefa, a professora passou para a fase de discussão com a apresentação das resoluções pelos grupos, seguida das sistematizações.

Percebemos que das oito equipes, cinco preencheram corretamente toda a tabela. No item $a$, cinco equipes concluíram que para calcular a área do quadrado, o software multiplica dois lados do quadrado. As outras três equipes tiveram um ou outro equívoco ao preencher a tabela, porém, responderam o item $a$ corretamente. Apresentamos a resolução correta de duas equipes. 
VIII Congresso Brasileiro de Informática na Educação (CBIE 2019)

Anais dos Workshops do VIII Congresso Brasileiro de Informática na Educação (WCBIE 2019)

\begin{tabular}{|l|c|c|c|c|c|c|c|c|c|c|c|}
\hline Lado do quadrado & 1 & 2 & 2,5 & 3 & 4,5 & 6 & 8 & 9 & 10,2 & 15 & 20 \\
\hline Área do quadrado & 1 & 4 & 6,25 & 9 & 20,25 & 36 & 64 & 81 & 1040,04225 & 400 \\
\hline
\end{tabular}

a) $\mathrm{O}$ que o GeoGebra fez para calcular a área dessas fiğuras?

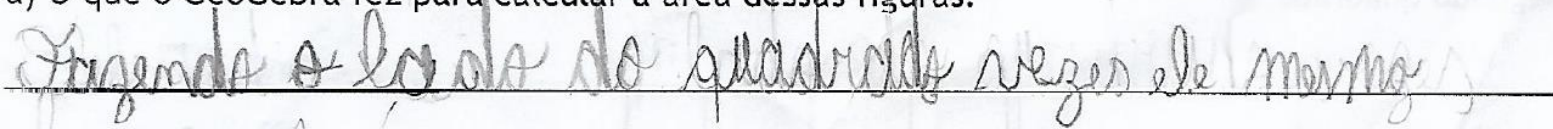

Figura 2. Resolução do grupo 3

\begin{tabular}{|l|l|l|l|l|l|l|l|l|l|l|l|}
\hline Lado do quadrado & 1 & 2 & 2,5 & 3 & 4,5 & 6 & 8 & 9 & 10,2 & 15 & 20 \\
\hline Área do quadrado & 1 & 4 & 6,25 & 9 & 0 & 36 & 64 & 81 & 0 & 0 & 2 \\
\hline
\end{tabular}

a) 0 que 0 GeoGebra fez para calcular a área dessas figuras?

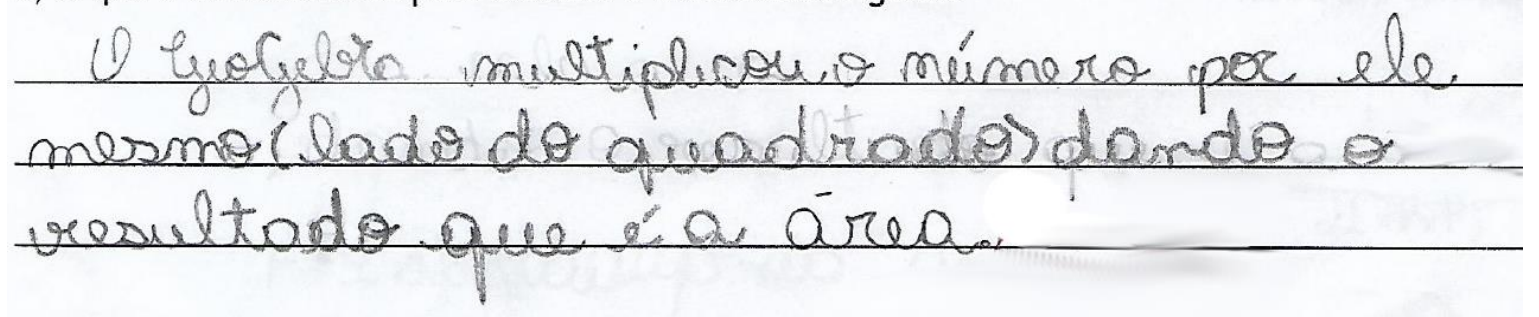

Figura 3. Resolução do grupo 7

Com relação ao item $b$, apenas quatro equipes concluíram de que forma o GeoGebra calculou o lado do quadrado conhecendo a área. Optamos por apresentar apenas duas resoluções corretas, pois as demais seguem o mesmo raciocínio.

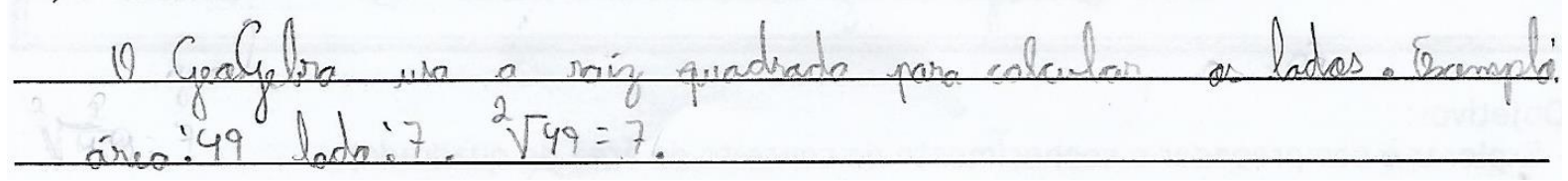

Figura 4. Resolução do grupo 1

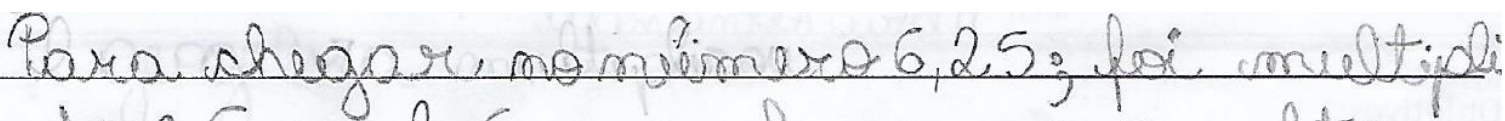

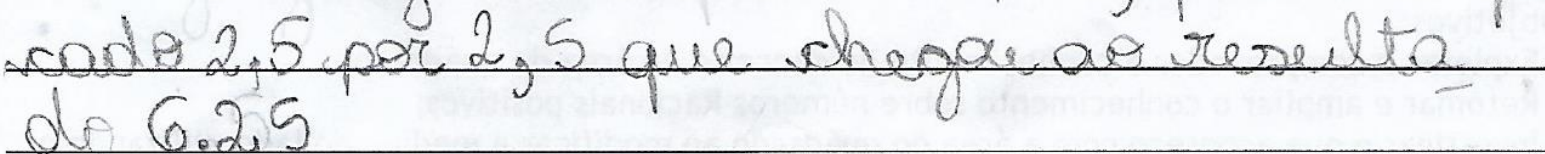

Figura 5. Resolução do grupo 6 
VIII Congresso Brasileiro de Informática na Educação (CBIE 2019)

Anais dos Workshops do VIII Congresso Brasileiro de Informática na Educação (WCBIE 2019)

Quanto ao item $c$, seis equipes conseguiram estabelecer algum tipo de relação entre a área do quadrado e a medida do seu lado. Destacamos a resolução do grupo 8 , a qual se assemelha com as resoluções dos grupos 2, 4, 5, 6 e 7 .

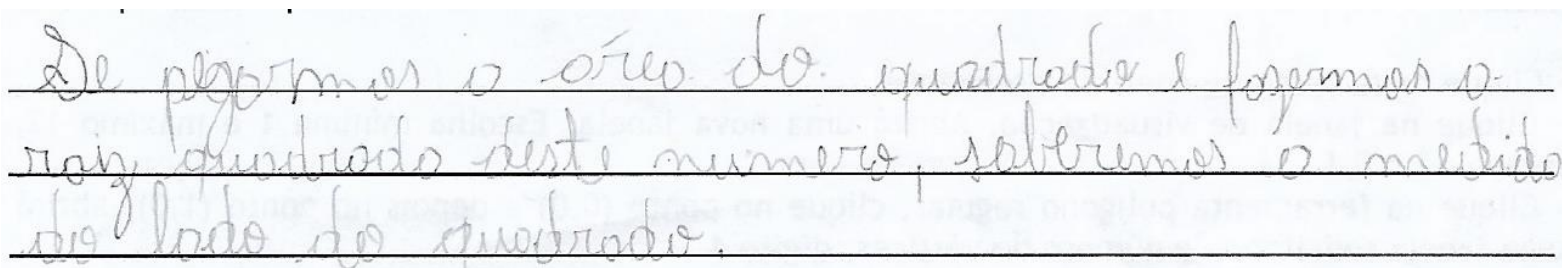

Figura 6. Resolução do grupo 8

Para o item $d$, todos entenderam que a área é lado vezes lado, porém não conseguiram representar algebricamente. No entanto, conseguiram apresentar a ideia por meio da linguagem escrita e com desenhos. Das oito equipes, cinco chegaram à conclusão de que a área do quadrado é $l^{2}$. Acreditamos que isso se deve ao fato de a professora, durante as aulas de potenciação no início do ano, ter mencionado o uso de letras para representação de números em certas situações matemáticas.
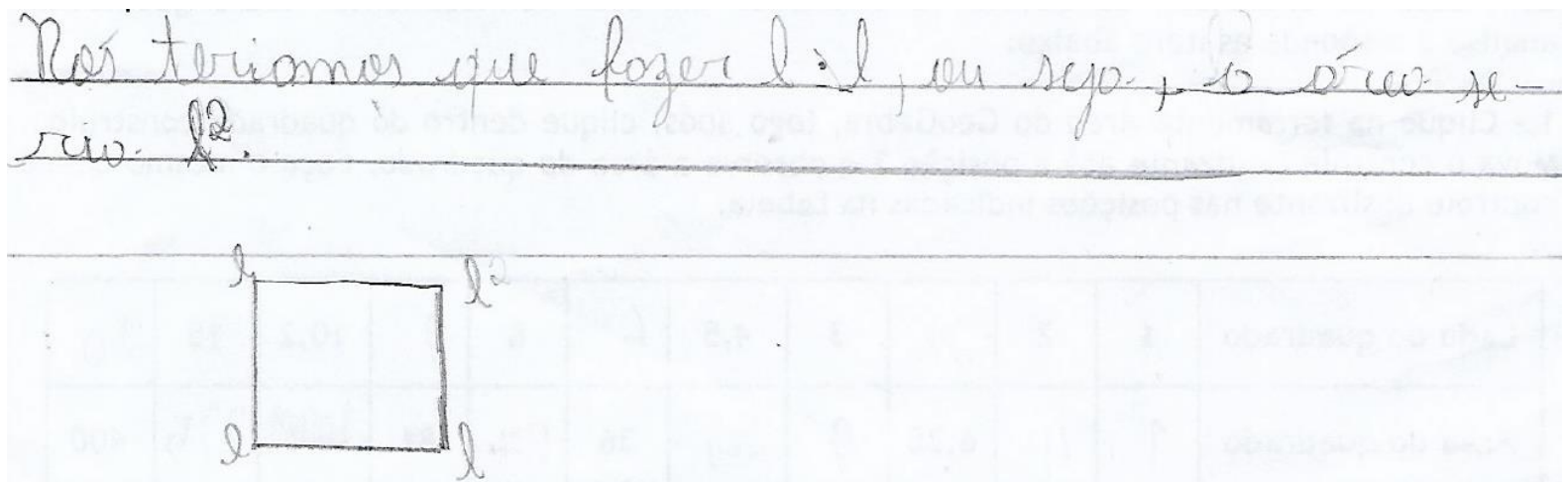

Figura 7. Resolução do grupo 8

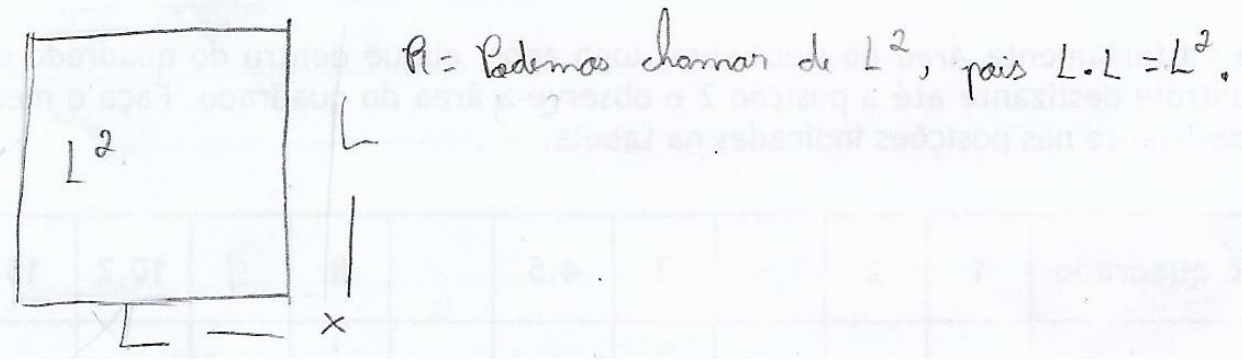

Figura 8. Resolução do grupo 1

Alguns alunos chegaram a representar e a escrever a relação pedida, porém não conseguiram expressar a potenciação corretamente. 


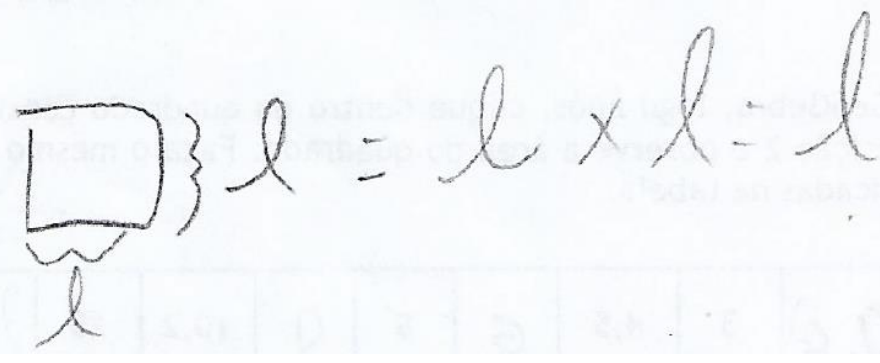

Figura 9. Resolução do grupo 7

No item $e$, cinco grupos chegaram à conclusão de que a área do quadrado cujo lado foi duplicado é o quádruplo do primeiro quadrado. Todos os grupos fizeram sua justificativa utilizando o software GeoGebra.

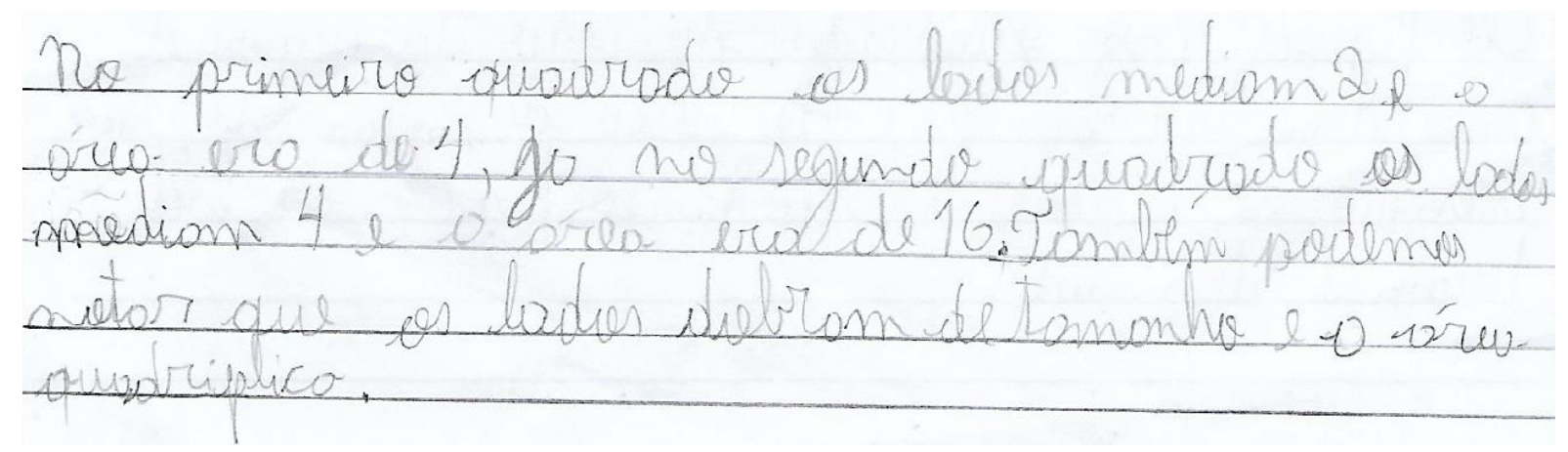

Figura 10. Resolução do grupo 8

O grupo 1 desenvolveu o item $e$ no GeoGebra, mas optou por responder em forma de desenho, afirmando ser mais fácil de justificar.
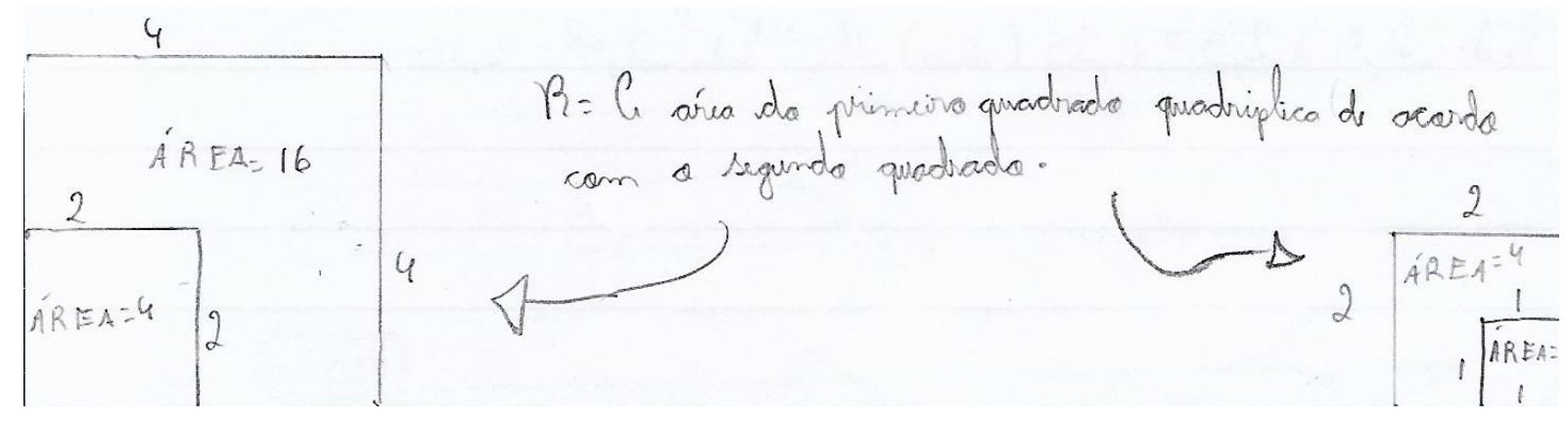

Figura 11. Resolução do grupo 1

A professora optou pela discussão coletiva da tarefa de cada item. Para isso, escolheu dois grupos para apresentarem suas ideias e conjecturas de cada item, sendo: um grupo que tenha cometido algum tipo de equívoco e outro que tenha resolvido corretamente.

\section{Reflexões Sobre a Aula}


VIII Congresso Brasileiro de Informática na Educação (CBIE 2019)

Anais dos Workshops do VIII Congresso Brasileiro de Informática na Educação (WCBIE 2019)

Diante das nossas experiências enquanto professoras, nos deparamos com dificuldades que os alunos apresentam na compreensão de conceito de área de quadrados. Apesar de ser um conteúdo que os alunos já deveriam ter aprendido nos anos anteriores, geralmente chegam ao $6^{\circ}$ Ano do Ensino Fundamental com essa defasagem. Pensamos, então, em planejar e desenvolver uma tarefa que possibilitasse a compreensão desse conceito.

Foi desafiador planejar uma tarefa na perspectiva do Ensino Exploratório de Matemática, pois foi nossa primeira experiência. Mais desafiador ainda, tanto para a professora quanto para os alunos, foi implementar a tarefa na turma, acostumada a ter aula nos moldes de ensino tradicional. Apesar disso, foram muito receptivos quanto ao desenvolvimento da tarefa.

Depois de apresentada a tarefa e respondidas todas as dúvidas, percebemos, por meio de audiogravações, a comunicação e interação entre os alunos, além de alunos e professora. O quadro de antecipação realizado antes do desenvolvimento da tarefa auxiliou a professora, acostuma a validar ou refutar respostas, a não fazer isso e sim questionar, solicitar justificativas, incentivar a comunicação oral e escrita das ideias dos alunos, de forma clara. A maioria dos grupos teve dificuldades quanto a escrita de suas justificativas, sendo que o item $b$, calcular o lado do quadrado conhecendo a área, foi o que apresentou maior quantidade de justificativas erradas.

No momento da socialização, alguns alunos se mostraram inseguros na exposição de suas estratégias de resolução. No entanto, a professora incentivou a comunicação, valorizando as ideias, mesmo que estivessem equivocadas, buscando a compreensão do erro. Dessa forma, após as interações e socializações de todos os itens, a professora finalizou a aula, fazendo a sistematização da resolução da tarefa.

$\mathrm{Na}$ sistematização, a professora chamou atenção para o item $b$, pois alguns grupos justificaram que para calcular o lado seria necessário realizar divisão, conhecendo a área do quadrado. Porém, a professora questionou como isso aconteceria para outros números, como saber por qual número dividir? Então, um dos alunos argumentou que não se tratava de uma divisão e sim um cálculo de raiz quadrada. Nesse momento, a professora validou o que o aluno falou, retomando o conceito de raiz quadrada. Para o item $d$, foi retomado o conceito de potenciação, já que alguns grupos equivocaram-se escrevendo que $l \times l=l$.

Para sistematizar o item $e$, optamos por apresentar uma tabela relacionando o lado, o dobro do lado do quadrado e suas respectivas áreas:
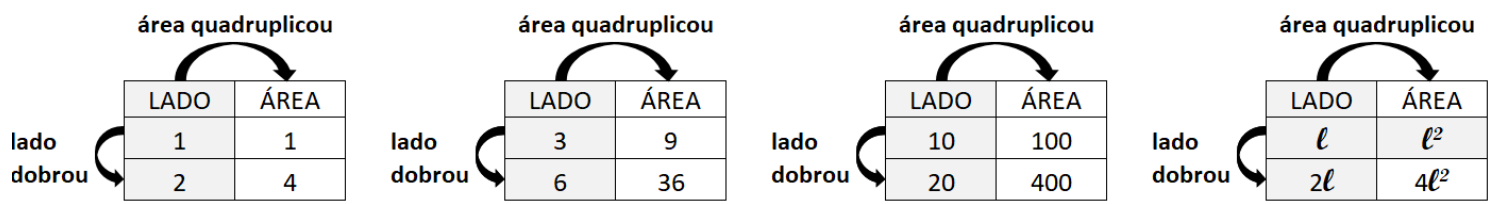

Figura 12. Sistematização do item e da tarefa Quadrados

Quanto ao uso do software GeoGebra, alguns alunos apresentaram menos habilidade de manipulação, no entanto, os próprios colegas auxiliaram para superação dessas dificuldades. 
VIII Congresso Brasileiro de Informática na Educação (CBIE 2019)

Anais dos Workshops do VIII Congresso Brasileiro de Informática na Educação (WCBIE 2019)

No viés da experimentação, visualização, simulação e relação dos cálculos com a geometria, o software GeoGebra pode atender a todos esses requisitos e potencializar o ensino e a aprendizagem de matemática [Basniak, Silva e Gaulovski 2017].

Ao usar o GeoGebra para o desenvolvimento da tarefa, é necessário que o aluno organize e interprete os dados inseridos no computador, usando a ferramenta como instrumento de aprendizagem e não apenas como um artefato tecnológico [Basniak e Estevam 2019].

No caso da tarefa Quadrados, ao construir um quadrado de lado qualquer

[...] ele precisará relacionar conhecimentos sobre as propriedades do quadrado, as medidas de ângulos, retas, segmentos de retas e, enfim, outros mais, dependendo da(s) estratégia(s) que utilizar. O aluno precisa utilizar sua experiência e conhecimentos anteriores para conseguir se comunicar com o computador, interpretando as respostas retornadas por ele, e/ou ainda comunicar seus achados e reflexões com o professor e colegas, colaborando com sua aprendizagem e com a dos demais para que consigam, todos, resolver a tarefa proposta [Basniak e Estevam 2019 p. 744].

Assim, considerando a experiência vivenciada, acreditamos que a aula desenvolvida por meio da perspectiva do Ensino Exploratório da Matemática, aliada à tecnologia, contribui para a expansão e compreensão da comunicação matemática, oral e escrita. Percebemos também, que o GeoGebra pode trazer contribuições para o Ensino Exploratório de Matemática permitindo a visualização e interpretação simbólica dos conceitos matemáticos, favorecendo ainda a percepção e concepção dos objetivos da tarefa proposta. Ademais, nesse processo, o aluno é inquirido e, dessa forma, utiliza e interpreta diferentes formas de representações matemáticas estimulando e articulando pensamentos matemáticos sistematizados, além de se comunicar de forma coletiva e individual.

Para nós, a experiência proporcionou uma reflexão sobre o nosso desenvolvimento profissional, além de permitir vivenciar o ensino na perspectiva exploratória. Sabemos que se trata de uma mudança de atitudes e habilidades do professor, que ao invés de estar no centro da aula, assume o papel de mediador. Contudo, refletindo sobre essa experiência, acreditamos ser necessário desenvolver outras tarefas assentes no Ensino Exploratório de Matemática, aliadas ao software GeoGebra, para que esse tipo de aula seja efetivada em nossas práticas profissionais, nessa metodologia de ensino que é ativa, inovadora e desafiadora.

\section{Referências}

Basniak, M. I. (2014) "Políticas de Tecnologias na Educação: o Programa Paraná Digital”. Tese (Doutorado em Educação). Universidade Federal do Paraná, Curitiba. https://acervodigital.ufpr.br/handle/1884/36372, Fevereiro.

Basniak, M. I. e Estevam, E. J. G. (2019) "Uma Lente Teórica para Analisar o Potencial das Tecnologias Digitais do Ensino Exploratório de Matemática. Acta Latinoamericana de Matemática Educativa, no prelo, v. 32, n.2, p. 738-747.

Basniak, M. I., Silva, S. C. R. and Gaulovski, J. M. (2017) “Tecnologias Digitais e Ensino da Matemática no Brasil: Uma Revisão da Literatura de 2010-2017'. Revista Tecnologias na Educação. ano 9, v. 23, dez.

Canavarro, A. P. (2011) “Ensino Exploratório da Matemática: Práticas e Desafios”. Lisboa: Universidade Aberta. 
VIII Congresso Brasileiro de Informática na Educação (CBIE 2019)

Anais dos Workshops do VIII Congresso Brasileiro de Informática na Educação (WCBIE 2019)

Cyrino, M. C. C. T e Teixeira, B. R. (2016) "O Ensino Exploratório e a Elaboração de um Framework para os Casos Multimídia. In Cyrino, M. C. C. T. (Org.). Recurso Multimídia, para Formação de Professores que Ensinam Matemática: Elaboração e Pperspectivas. $1^{\mathrm{a}}$ ed. Londrina: Eduel. p. 83-99.

GeoGebra (2019) http://www.geogebra.org, Maio.

Oliveira, H., Menezes, L. e Canavarro, A. P. (2013) "Conceptualizando o Ensino Exploratório da Matemática: Contributos da Prática de uma Professora do 3. ${ }^{\circ}$ Ciclo para a Elaboração de um Quadro de Referência”. Quadrante, v.22, n.2, p.1-25.

Paraná (2008) “Diretrizes Curriculares da Educação Básica Matemática”. Seed, Curitiba.

Ponte, J. P. (2005) "Gestão Curricular em Matemática”. In GTI (Ed.). O Professor e o Desenvolvimento Curricular. Lisboa: APM, p.11 -34.

Unesco (2016) “Os Desafios do Ensino de Matemática na Educação Básica”. São Carlos: EdUFSCar. 